\title{
Visual search through word lists as a function of grade level, reading ability,
} and target repetition*

\author{
RON LESLIE and ROBERT C. CALFEE† \\ University of Wisconsin, Madison, Wisconsin 53706
}

Second-, fourth-, and sixth-grade students of high or low reading ability and college students carried out a visual-search task in which they scanned a list of 10 words, looking for a target word which was changed every trial or remained constant during an entire session. Search time increased linearly with serial position, consistent with a serial self-terminating model of visual search. The search rate increased from 3.3 words/sec in the second grade to 8.4 words/sec in college. Reading ability was not a significant factor in any comparisons. These results on the development of visual-search ability agree with others in showing that with increasing age there is a marked increase in search speed. However, retarded readers are as competent as their age peers on this task, suggesting that reading dysfunction must be traced to other deficiencies.

In a landmark study, Neisser, Novick, and Lazar (1963) found that after extensive practice and under instructions which stressed speed, the Ss were able to search through a list of 50 six-letter strings at the same rate (about 10-12 strings/sec) whether they were looking for a single target letter or as many as 10 . Increased visual distinctiveness between nontarget background items and target items increased scanning speed to about 20 strings/sec (Neisser, 1963). When the S's search was for targets defined by meaning rather than physical properties, search speed was slower, about 8 words/sec for states of the union and 5 words/sec for animals or proper names (Neisser \& Beller, 1965). In each of these studies, reaction time was a linear function of the serial position of the target in the list, which is consistent with a serial self-terminating model of visual search.

Several studies have looked at the development of visual search abilities. Gibson and Yonas (1966a), using procedures similar to those of Neisser, replicated the essential features of his study with second, fourth, and sixth graders and college students. There were either one or two target letters, and visual similarity between the target and the background items was either high or low. Search rate was unaffected by the number of targets but decreased significantly at the high level of visual similarity. Gibson and

*This research was supported in part by the Wisconsin Research and Development Center for Cognitive Learning with funds from the U.S. Office of Education, Contract OE 5-10-154, and in part by Grant MH 12637 to the second author from the National Institute of Mental Health.

+Now at Stanford University. Requests for reprints should be sent to Robert Calfee School of Education, Stanford University. Stanford, California 94305 .
Yonas (1966b) found that acoustic similarity had no effect on the search rate for either third graders or college students. Search rates in these studies, which employed much less practiced Ss than in Neisser's research, ranged from 3 strings/sec for second and third graders to 6 strings/sec for college students. (These rates are actually comparable to those reported by Neisser for Ss at about the same amount of practice.)

Forsman (1967) conducted a developmental study of visual search, employing nonsense shapes which varied in degree of symmetry and complexity. He also found that rate of search was about twice as fast in college students as in third graders, $5 \mathrm{items/sec}$ vs 2.5 items/sec.

The research above leaves unanswered several questions, both methodological and substantive. For example, in Gibson and Yonas (1966a) the two-target lists always followed the one-target lists. The absence of any difference between one and two targets may have resulted from the confounding with practice. Error rates are not always given, and Wattenbarger (1968) has shown that the tradeoff between speed and accuracy may significantly influence the effects of number of targets on search rate. Neisser et al (1963) did not find an increase in error rate as the number of targets was increased, but the error rate was greater than $20 \%$ for all conditions. Finally, in every one of the studies reported, all lists contained a target item and the $S$ was so informed. These conditions might well produce a bias toward speed at the expense of accuracy.

There is also some reason to question the applicability of these results to search by young children through word lists. A college student looking for a target letter such as " $\mathrm{K}$ " or a word such as "Monday" may be able to ignore semantic and word-association content in the background items. It is less clear that a younger, relatively unskilled reader searching for a common word can ignore the meaning or content of the background words. 1

The present investigation was designed to answer the following questions: (1) Are search rates through word lists comparable to the search rates through lists of letters found in previous experiments? (2) What is the effect of experience with specific targets on search rate? (3) What differences, if any, characterize visual search performance of good and poor readers.? The experiment also incorporated certain methodological improvements over previous studies.

\section{PROCEDURE}

\section{Subjects}

Forty-eight children ${ }^{2}$ attending a summer session, 16 each from Grades 2,4 , and 6, served as Ss. At each grade level, 8 children were from a remedial reading class and 8 from a remedial mathematics class. Children in the former group were a year or more behind grade level in reading ability, while the children in the latter group were reading at Grade Level 4. There were approximately equal numbers of boys and girls in each group. Eight college students from an introductory psychology class were also tested.

\section{Materials}

Four sets of 17 10-word lists were constructed by random selection from the 634 four-letter words in the cumulative vocabulary of the Ginn Basic Reader, Grade 3, with certain restrictions to be described. In two of the sets, designated constant-target (C), a single word was selected at random from the set to serve as the target word for all lists in that set. In the other two variable-target (V) sets, a different target word was selected for each list. Visual similarity was minimized by restricting the choice of words so that adjacent letters were never identical in the same position for any two words in a list (e.g., "most" and "fast" were not allowable in the same list). Phonetic similarity was also kept to a minimum.

'Ihe first 2 lists in each set were for practice (1 target list, 1 no-target list). In 10 of the 15 remaining lists, each serial position (SP) was tested exactly once, and the remaining 5 lists contained no target. Order of presentation of different SPs and no-target lists was random, with the restriction that not more than 2 no-target lists occurred in succession.

The 10 words in each list were 


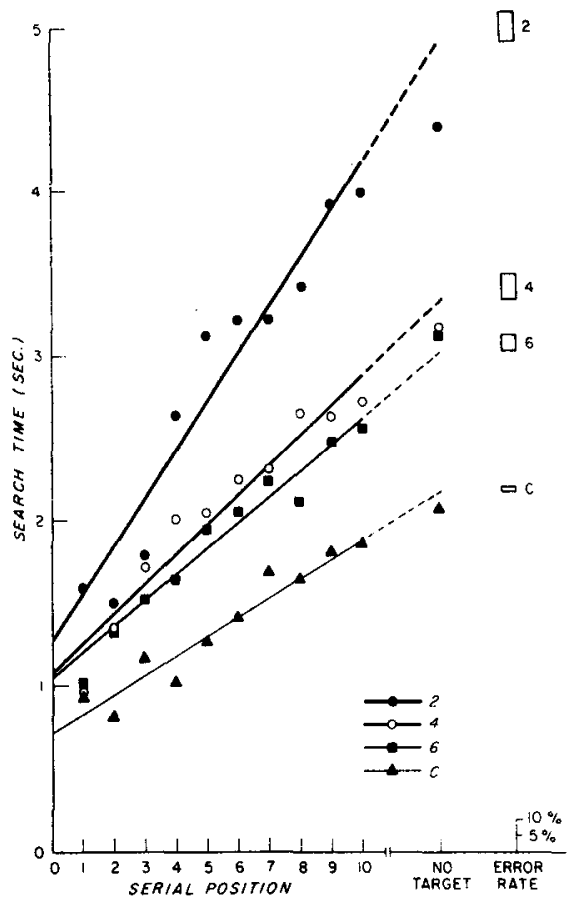

Fig. 1. Search time as a function of serial position of target in list for Grades 2, 4, and 6 and college students. No-target search time and error rates also shown. Linear function is least-squares fit to each data set.

typed in a vertical array in lowercase IBM Executive (sans serif). Individual letters subtended $.27 \mathrm{deg}$ of visual angle, the vertical spacing was .18 deg, the horizontal length of each word was $1.09 \mathrm{deg}$, and the vertical length of the array was $5.73 \mathrm{deg}$.

\section{Procedure}

Stimuli were presented in a Polymetric V-0959 two-channel tachistoscope. The fixation point marked the center of the top word in the list. Prior to each list, the $\mathbf{S}$ was shown the target word printed on a $3 \times 5$ card, and the $E$ also pronounced the word. The $S$ was instructed to focus on the fixation point carefully, then press a switch which presented the list. As soon as the target was spotted or it was determined that the list did not contain a target, the $S$ released the switch as quickly as possible. Reaction time between onset and offset was measured by a Standard Electric clock marked in .01 sec.

Each $S$ was tested on two different sessions each lasting about $15 \mathrm{~min}$. The two sessions were given 2 days apart. Instructions, in addition to describing the general procedure, also stressed the importance of careful fixation and of always scanning from top to bottom until the target word was spotted. The $\mathbf{S}$ was cautioned not to look up and down in a random fashion. He was also informed that

Table 1

Results of Analysis of Variance of Reaction Times (Significant Sources of Variation Only)

\begin{tabular}{|c|c|c|c|c|c|c|c|}
\hline \multirow[b]{2}{*}{ Source } & \multirow[b]{2}{*}{ df } & \multicolumn{3}{|c|}{ Target Lists } & \multicolumn{3}{|c|}{ No-Target Lists } \\
\hline & & MS & $\mathbf{F}$ & $\mathbf{p}$ & MS & $\mathbf{F}$ & $\mathbf{p}$ \\
\hline & \multicolumn{7}{|c|}{ Grade School } \\
\hline Design & \multicolumn{4}{|c|}{$\begin{array}{c}\text { Between: Grade, Reading } \\
\text { Level, Order } \\
\text { Within: SP, Target } \\
\text { Constancy }\end{array}$} & \multicolumn{3}{|c|}{$\begin{array}{c}\text { Between: Grade, Reading } \\
\text { Level, Order } \\
\text { Within: } \\
\text { Target } \\
\text { Constancy }\end{array}$} \\
\hline Grade & 2 & 81.5 & 17.8 & $<.001$ & 100.6 & 7.2 & $<.01$ \\
\hline $\begin{array}{l}\text { Target Constancy } \\
\text { SP }\end{array}$ & 1 & 8.6 & 15.5 & $<.001$ & 22.9 & 13.6 & $<.001$ \\
\hline Linear & 1 & 349.7 & 432.0 & $<.001$ & 一 & - & - \\
\hline Nonlinear & 8 & 1.6 & 2.0 & n.s. & 一 & - & - \\
\hline \multicolumn{8}{|l|}{ Grade by SP } \\
\hline Linear & 2 & 14.3 & 17.8 & $<.001$ & - & - & 一 \\
\hline Nonlinear & 16 & .8 & 1.0 & n.s. & 一 & - & - \\
\hline \multirow[t]{2}{*}{$\begin{array}{l}\text { Target Constancy } \\
\text { by Order }\end{array}$} & 1 & 3.0 & 4.7 & $<.05$ & 13.6 & 8.1 & $<.01$ \\
\hline & \multicolumn{7}{|c|}{ College } \\
\hline Design & \multicolumn{4}{|c|}{$\begin{array}{l}\text { Between: Order } \\
\text { Within: SP, Target Constancy }\end{array}$} & \multicolumn{3}{|c|}{$\begin{array}{l}\text { Between: Order } \\
\text { Within: Target Constancy }\end{array}$} \\
\hline $\begin{array}{l}\text { Target Constancy } \\
\text { SP }\end{array}$ & 1 & .1 & $<1.0$ & n.s. & .1 & $<1.0$ & n.s. \\
\hline Linear & 1 & 18.9 & 153.0 & $<.001$ & - & - & - \\
\hline Nonlinear & 8 & .2 & $<1.0$ & n.s. & - & - & - \\
\hline
\end{tabular}

some of the lists would not contain a target, and that both speed and accuracy were important. If the $S$ failed to detect the target word in a target list, that list was retested later in the session.

During one of the sessions, a $\mathrm{C}$ set was used, and for the other session, a $V$ set. Each of the two $C$ sets was paired equally often with each $\mathrm{V}$ set, and order of presentation of sets and $C$ and $\mathrm{V}$ conditions was balanced over sessions between the Ss.

\section{RESULTS AND DISCUSSION}

The major results are shown in Fig. 1, which gives mean reaction time and error probability for each grade level. Significant sources from the analyses of variance of the reaction times are presented in Table 1. Separate analyses were carried out on target and no-target data (SP was a variable in the first but not the second), and on grade-school and college data (reading level was a variable in the first but not in the second).

In the analysis of the grade-school target data, main effects of grade, target constancy, and SP were all significant, as was Grade by SP. The linear component of SP and Grade by SP accounted for all but a negligible portion of the variance attributable to these sources. The linear component of SP was the only significant source of variance in the analysis of the college target data. Grade and target constancy were significant main effects in the analysis of the grade-school no-target data. There was also a significant interaction of Target Constancy by Order which is uninterpretable. There were no significant sources of variance in the college no-target data.

These analyses mean that the data are adequately described by linear functions relating SP to reaction time in Fig. 1. We will follow the lead of Neisser (1967) and Sternberg (1969) in identifying the intercept with decision operations, and the slope with the time required to scan or visually process each word in the list. There is a steady decline in both parameters from second grade through college. The intercept decreases slightly from second through six th grade and drops more abruptly from sixth grade to college. However, the major effect of grade level is a change in the slope parameter; the search rate increases steadily from 3.3 words/sec in second grade to 8.4 words/sec in college.

The significant main effects of target constancy in the grade-school data result mainly from a slightly higher intercept parameter. Average search time was 189 msec less on C than on $\mathrm{V}$ targets. The linear component of the Target Constancy by SP interaction was not significant in any analysis, which means that target constancy did not have a statistically significant effect on search rate. However, the slope parameter was slightly higher in the $\mathrm{V}$ condition than the $C$ condition in both the grade-school groups, $216 \mathrm{msec}$ vs $204 \mathrm{msec}$, and college group, $134 \mathrm{msec}$ vs 105 msec.

The main effects of reading level were not significant, nor did this variable enter into any significant interactions; all F-ratios for this factor were less than 1.5 , as were interactions 
of reading level with the linear and nonlinear components of SP. Close scrutiny of the data failed to reveal any perceptible effects of this variable of any sort.

There was a decrease in error rate from the second through the sixth grade, but it was not statistically signific ant. The high-reading-level group made slightly, but not significantly, more errors than the low-reading-level group. The bulk of the errors (70 out of 76 ) were failures to locate the key word on target trials. The six errors on no-target trials were distributed evenly over grades and groups.

With regard to the questions posed earlier: (1) Visual search through word lists is similar to the process of search through lists of letters under all experimental conditions and for all populations examined. The linearity between SP and reaction time is evidence of a serial self-terminating process. In a sense, this result means that all Ss were able to follow the instructions to start at the top of the list and scan down one item at a time, without wandering. It also means that the search rate was fairly constant at all positions. The slope parameters are about the same for words as for letters (given a limited amount of practice) at each grade level-around $300 \mathrm{msec} /$ item early in grade school, dropping to $100 \mathrm{msec} / \mathrm{item}$ in college. In other words, searching through a string of four letters for a particular letter and determining whether a four-letter string matches a target word take about the same amount of time for $S s$ of a given age. (2) Although overall search time was less with $\mathrm{C}$ than with $\mathrm{V}$ targets, there are no significant effects of target constancy on search rate. This result may be specific to the familiar words used as targets and context words in this study, and to the relatively limited amount of practice. (3) Reading ability is not a significant factor in performance on this task. For retarded readers of the sort included in this experiment, the scanning process does not differentiate them from their more able peers. Their difficulty must thus be traced to some other function, such as letter-sound decoding, word attack, comprehension, or integration of larger chunks of information. This result is encouraging since it suggests that reading deficiency does not produce a generally lower level of functioning on all cognitive tasks. Rather, the results indicate that some degree of localization of deficit in specific skills is possible.

\section{REFERENCES}

FORSMAN, $R$. Age differences in the effects of stimulus complexity and symmetrical form on choice reaction and visual search performance. Journal of Experimental Child Psychology, 1967, 5, 406-429.

GIBSON, E. J., \& YONAS, A. A developmental study of visual search behavior. Perception \& Psychophysics. 1966a, 1, 169-171.

GIBSON, E. J., \& YONAS, A. A developmental study of the effects of visual and auditory interference on a visual scanning task. Psychonomic Science, $1966 \mathrm{~b}, 5,163-164$.

NEISSER, U. Decision time without reaction time: Experiments in visual scanning. American Journal of Psychology, 1963, 76, 376-385.

NEISSER, U. Cognitive psychology. New York: Appleton-Century-Crofts, 1967.

NEISSER, U., \& BELLER, H. K. Searching through word lists. British Journal of Psychology, 1965, 56, 349-358.

NEISSER, U., NOVICK, R., \& LAZAR, R. Searching for ten targets simultaneously. Perceptual \& Motor Skills, 1963, 17, 955-961.

STERNBERG, S. The discovery of processing stages: Extensions of Donder's method. In W. G. Koster (Ed.), Attention and performance II. Amsterdam: North-Holland, 1969.

STRONGMAN, K. T., \& BROWN, R. Visual search with meaningful and non-meaningful material. Quarterly Journal of Experimental Psychology, $1967,19,164-168$.

WATTENBARGER, B. L. Speed and accuracy set in visual search performance. Paper read at meeting of the Midwestern Psychological Association, Chicago, 1968.

\section{NOTES}

1. There is not a great deal of research regarding the effects of visual or semantic similarity on rate of visual search through word lists. In one study that is relevant, Strongman and Brown (1967) had Ss look through 10-word lists for a real word in a background of nonsense syllables or for a nonsense syllable in a background of real words. The familiarity of background and target items was high or Iow, and Ss received positive or negative instructions (e.g., "pick out a word which is meaningful" vs "pick out a word which is not a nonsense word"). These variables were combined factorially in a $2^{4}$ design. With positive instructions, words took longer to locate in a context of low familiarity than high-familiarity nonsense syllables, and nonsense syllables took longer to locate in a context of unfamiliar than of familiar words. The familiarity of the context was a significant variable, and (aside from the distinction between words and nonsense syllables) the familiarity of the target items had relatively little effect. With negative instructions, it was again true that as the semantic distance between target and context increased, search became faster. However, the familiarity of both context and target were significant variables. For example, familiar target words took $\mathbf{5 8}$ sec to search for, unfamiliar target words .75 sec, when $S$ was instructed to look for "something that was not nonsense," whereas when S was instructed to look for a word, search rate was $.71 \mathrm{sec} /$ word for familiar words $.72 \mathrm{sec} / \mathrm{word}$ for unfamiliar words. These results indicate that semantic relations between target and background words must be considered in interpreting the results of visual search. The Strongman-Brown results cannot tell how pervasive the influence of semantic factors might be. Their particular task requires much more complete analysis of target-context relations than when $S$ is instructed to look for a specific word. The difficulty of the task is seen in the slow search rates -2 items/sec or slower.

2. The children in this experiment were from several different schools in the area. In each case, the child had been found to be reading at 1-3 years below grade level on some standardized reading test. There was not a district-wide test program, and the variety of tests used to evaluate the students was so widespread that detailed analysis of the actual reading scores would be meaningless. The impression of the reading specialist who was directing the program was that all students in our sample could be properly classified as moderate to severely retarded.

(Accepted for publication Febraury 7, 1971.) 